\title{
REVIEW OF BUCKLING IN VARIOUS STRUCTURES LIKE PLATE \& SHELLS
}

\author{
Amit Patil $^{1}$, Amol Kolhe ${ }^{2}$, Abdul Sayeed AW Shaikh ${ }^{3}$ \\ ${ }^{I}$ Asst. Professor Department of Mechanical Engineering, Pad. DR D Y Patil Institute Engineering \& Technology, Pimpri, \\ Pune Maharashtra, India \\ ${ }^{2}$ Asst. Professor Department of Mechanical Engineering, Pad. DR D Y Patil Institute Engineering \& Technology, \\ Pimpri, Pune Maharashtra, India \\ ${ }^{3}$ Asst. Professor Department of Mechanical Engineering, P.R.Pote (Patil) College of Engineering \& Management, \\ Amravati, Maharashtra India
}

\begin{abstract}
This paper represents discussion about the Buckling mechanism in the cylindrical vessels and plates as buckling is characterized by sudden failure of structural member subjected to high compressive stress, where the actual compressive stress at the point of failure is less than the ultimate compressive stresses that the material is able to withstand. Pressure vessels are the equipments which are used for the storage of gases or liquids at specific temperature and pressure condition. The load carried by these pressure vessels also imparts forces on its shell structure which are likely to be buckle
\end{abstract}

Keywords: buckling, cylinder, shell, FEA, Investigation

\section{INTRODUCTION}

Basically buckling is the phenomenon associated with failure of column like structures which are having more length. In the design of structures like pressure vessel, piping systems there are mainly two concerns viz; 1.Abiliy to support specified load without experiencing excessive stresses.2 Ability of the structure to support a specified load without undergoing unacceptable deformation. The failure of vessels depends upon factors such as, type of vessel, Support conditions, Type of load, and Materials used. If we consider shell of the pressure vessel, due to its size its axial displacement is going to be small as compared to its lateral deflection it may be termed as buckling. The main objective of this review paper is to discuss the work of various researchers on this buckling phenomenon with regards to all types of vessels, piping systems, plates etc.

\section{LITERATURE REVIEW}

W. Guggenberger a, R. Greiner a, J.M. Rotter ${ }^{\text {b,* }}$ (2000) the authors have presented work on the buckling behavior of cylindrical shells provided with discreet supports. This work has been carried out in the elastic-plastic range which results in complications and suggests more work need to be. for defining buckling strength for the design of structures. The nature of the study is linear \& non - linear behavior of the cylinders with discrete supports, for given loading conditions.

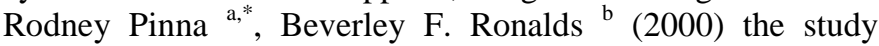
focuses on the buckling of shells subjected to hydrostatic loadings. The study is carried out with various boundary conditions and for different cases such as shell with one end pinned other free, shell with intermediate length, shell with open end. .G. Teng ", F. Chan ${ }^{1}$ (2000) the study is all about the elastic buckling strength of T-shaped ring beam used for Tanks. The paper focuses on the new approximation by using the effective section method to relate the loading on tank with circumferential compressive stresses. The interpolation formula developed by Jumikis and Rotter for annular plate ring beams is found to be useful for T-shaped ring beams. S. Kyriakides", T.A. Netto (2000) the authors have presented study on the dynamics of propagation of buckles in pipelines under external pressure. The analytical study has been carried out with Finite Element Model with ability to simulate dynamics of buckle propagation and results are validated by experimental results. G. Michel *, A. Limam, J.F. Jullien (2000) the authors have presented study on the buckling of cylindrical shell with static \& dynamic loadings due to seismic activity. Finite Element Model simulation helped to know the effect of vibration excitation which results into the large deformations and decrease in the stiffness of the shell. G. Michel ${ }^{\text {a }}$, A. Combescure ${ }^{\mathrm{b}}$, J.F. Jullien ${ }^{\mathrm{a}}, *$ (2000) the authors have presented research work on the dynamic buckling of the cylinders under shear loading with the help of FEM based simulation. First part of study talks about the experimentation and FEM codes being used. Second part of the study shows static tests and FEM calculations done. Third part is the discussions of dynamic results. Hui-Shen Shen (2001) the authors have presented research work on post buckling analysis of shear deformable cross-ply laminated cylindrical shell under combined action of external pressure and axial 
compression. The study accounts for nonlinear pre buckling deformations and initial geometric imperfections of the shell along with boundary layer theory of shell buckling. With the help of single perturbation method interactive buckling loads and post buckling equilibrium paths were determined. Mark W. Hilburger ${ }^{\mathrm{a}, \mathrm{c}},{ }^{*}$, Vicki O. Britt ${ }^{\mathrm{b}}$, Michael P. Nemeth ${ }^{\mathrm{c}}$ (2001) the authors have presented research work on buckling behavior of compression -loaded quasi-isotropic curved panels with a centrally located circular cutout by analytical and experimental method. Analytical results are generated with the help of Finite Element Method which consists of the effects of elastic circumferential edge restraints on the pre buckling and buckling response of a selected panel.Resuts shows that due to circumferential edge restraints there will be significant rise in buckling load. I.P. Pasqualino*, S.F. Estefen (2001) this study is all about the non linear buckling propagation seen in deepwater piping system. The study consists of thin shell theory, elastic-plastic behavior of materials. Finite difference method for solving equilibrium equations, at last all the experimental data $\&$ numerical results are correlated. Carl T.F. Ross, Andrew P.F., Little (2001) the authors have presented work on corrugated carbon fiber cylinder subjected to external pressure resulting into buckling. For the purpose of theoretical study by using axisymmetric thin-walled shell elements Finite element model is prepared. Experimental results are based on strain gauges. Comparison of both results shows that experimental results are good. Jianghong Xue , Michelle S. Hoo Fatt ${ }^{*}$ (2001) this study is all about the buckling pressure propagation in the pipelines with non-uniform thickness. However the results of this study are forming basis for the buckling pressure propagation in the corroded pipes which will fail either by shell buckling or the local buckling. Gyeong-Hoi Koo*, Bong Yoo, Jong -Bum Kim (2001) this paper is a study of finding out the buckling strength and buckling mode shape of the reactor vessel of the Korea advanced liquid metal reactor (KALIMER) subjected to seismic loads. The study is carried out by means of numerical simulation methods, Eigen value buckling analysis, non-linear buckling analysis with and without the effect of plasticity. X. H. Shi ${ }^{a, b}{ }^{*}$, Y. G. Gao ${ }^{a, b}$ (2001) this paper shows that the concept of generalized new dimensionless number, response number $\mathrm{R}_{n(n)}$ used for the study of elastic, plastic, dynamic elastic, dynamic plastic buckling problems of plates, columns and shells. Michelle S. Hoo Fatt", Jianghong Xue (2001) The authors have presented research work on the buckling pressure propagation in the corroded pipelines. The study is supported by deriving Rigid-plastic solutions for the steady-state, quasistatic buckle propagation pressure in corroded pipelines and comparing with the finite element results (ABAQUS). X. Wanga; *,G.Lub, D.G. Xiao ${ }^{\text {a }}$ (2002) this paper shows the study carried out for non-linear thermal buckling behavior of local delamination near the surface of fiber-reinforced laminated cylindrical shell. Young's modulus and coefficient of thermal expansion are treated as function of temperature. With the help of energy principle critical temperatures, different stacking pattern, and different radius of shell are obtained. Walter Wunderlich, Ursula Albertin (2002) the authors have presented work on the buckling behavior of spherical shells subjected to external pressure with very limited information. The present study is carried out for spherical shells for defining new design rules with relevant details like boundary conditions, material properties and imperfections. Mark W. Hilburger, James H. Starnes Jr. (2002) the authors have presented work on analytical as well as experimental study of effects of imperfections on the nonlinear buckling behavior of thin walled compression loaded graphite-epoxy cylindrical shells. The research comprises of traditional and non- traditional imperfections. Non-linear static and non-linear transient analysis of shell is carried out. SeungEock Kim , Chang-Sung Kim (2002) the objective of this research work is to evaluate buckling strength of geometrically perfect and imperfect cylindrical shells and tanks subjected to axial compressive load. Numerical analysis is carried out with sue considerations to modeling method, element type and required number of elements. J. Błachut ${ }^{*}$ (2002) the author has presented theoretical as well as experimental study on buckling of barreled shells subjected to external pressure. During the study sensitivity of buckling, geometric imperfections are also studied. C.A. Schenk, G.I. Schuëller (2003) the authors have presented study of buckling analysis of thin-walled cylindrical shells with random geometric imperfections axial compressive load. Numerical study is done by using direct Monte Carlo Simulation in context with finite element method. C.T.F. Ross ${ }^{{ }^{*}}$, Bak Hock Huat $^{\mathrm{a}}$, Tay Boon Chei ${ }^{\mathrm{a}}$, Chai Min Chong ${ }^{\mathrm{a}}$, M.D.A. Mackney ${ }^{\mathrm{b}}$ (2003) the authors have presented study on the buckling of GRP Hemi-ellipsoidal dome shells with different aspect ratio under external hydrostatic pressure. Theoretical study is carried out by using finite element method in which both material and geometry non-linearity taken into account. ChoChung Liang ${ }^{a^{*}}$, Hung-Wen Chen ${ }^{b}$ (2003) the authors have presented study on the optimum design of fiber-reinforced composite cylindrical skirts used for rocket motor casing subjected to buckling. A skirt is a potential element for weight reduction in rocket motors as it leads to reduction of the total weight of solid rocket motor. Due to its significance for solid rocket motors, the aim of this paper is to investigate the optimum design under aerodynamic torque and axial thrust. Classical lamination theory is used for the weight optimization of rocket casing. M. Özakca ${ }^{*}$, N. Taysi, F. Kolcu (2003) the authors have presented buckling analysis of annular and circular plates with finite element approach. Through number of buckling analysis parameters like accuracy, efficiency and convergence are explored. P.K. Das ${ }^{\text {a,* }}$, A. Thavalingam ${ }^{\text {a }}$, Y. $\mathrm{Bai}^{\mathrm{b}}$ (2003) the main aim of this research work is to evaluate buckling and ultimate strength of ring stiffened shells subjected to various modes of buckling due to axial compressive load, radial pressure and combined loading. Parameters like bias and coefficient of variation are calculated for reliability study. Azam Tafreshi ${ }^{\text {a,** }}$, Tobias Oswald ${ }^{\mathrm{b}}$ (2003) this paper talks about the Finite element models developed for studying global, local and mixed mode buckling behavior of 
composite plates with embedded delaminations under compression. The global modelling results were compared with corresponding experimental results. It is shown that the numerical results for embedded delaminations agree very well with the experimental results. In the course of global buckling, a parametric study was carried out to identify the influence of the delamination size, shape and alignment of a series of composite plates. G.H. Nie* (2003) the author has presented work on non-linear analysis of elastically restrained imperfect shallow spherical shells on pasternak foundation. By adopting the asymptotic iteration method (AIM), an analytical expression concerning the external load and the central deflection of the shell is derived in a non-dimensional form. Various parameters like geometrical imperfection, extensional and shear moduli of foundation and edge-restraint coefficients as well as structural geometry are also considered which are useful for buckling analysis of the structure. L. Grünitz ${ }^{*}(2003)$ the author has presented his research work on the effect of welding on the buckling behavior of a spherical cap used in tank closures, roofs and marine structures. This paper aims to determine the buckling strength of clamped and hinged spherical caps under uniform pressure with a circumferential weld depression by using the finite element method. N. Ganesan , V. Pradeep (2005) the authors have presented research work on the buckling \& vibration of cylindrical shell using FEA. Free vibration analysis carried out by considering initial stress effect and added mass effect due to hot liquid. Z.G. Wei ${ }^{a, b}$, J.L. Yu ${ }^{a, *}$, R.C. Batra ${ }^{b}$ (2005) the authors have presented research work on the Dynamic buckling of thin cylindrical shells under axial impact by analytical and numerical method. Analytical study is based on the assumption of the stressed/deformed state of a shell. The finite element method is used to analyze the collapse of an imperfect circular cylindrical tube with axial impact $\mathrm{B}$. Skalleruda ${ }^{{ }^{*}{ }^{a}}$, K. Holthe ${ }^{a}$, B. Haugen ${ }^{b}$ (2005) the main aim of this research work is to evaluate Thin shell and surface crack finite elements for simulation of combined failure mode analysis. It consists of combination of a rectangular assumed natural deviatoric strain thin shell finite element and an improved linespring finite element. Roberto Brighenti ${ }^{*}(2005)$ the main aim of this research work is to study the buckling behavior of cracked rectangular elastic thin plates under tension or compression, by considering the effects of various geometrical, mechanical and boundary conditions of the problem. With the help of finite element method several numerical parametric analyses are performed, in order to determine the critical load multiplier, in compression or in tension, by varying some of the problem's geometrical and mechanical parameters. B.P. Patel ${ }^{\text {a, }}$, K.K. Shukla ${ }^{b}$, Y. Nath ${ }^{c}$ (2005) the authors have presented work on , thermoelastic postbuckling behavior of cross-ply laminated composite conical shells under uniform temperature distribution The finite deflection analysis is carried out to find out the relationship between the maximum deflection and the temperature rise, and to evaluate the minimum temperature parameter that causes the shell deformation from axisymmetric deformation mode to asymmetric one. Henrique Santos a , Cristo' va o M. Mota Soares a,", Carlos A. Mota Soares ${ }^{a}$, J.N. Reddy ${ }^{\mathrm{b}}$ (2005) this paper talks about the general semi-analytical finite element model developed for bending, free vibration and buckling analysis of shells made of laminated orthotropic elastic material. The 3D elasticity theory is used and the equations of motion are obtained by expanding the displacement field. J. Mark F.G. Holst", J. Michael Rotter (2005) this paper talks about the study of initiation and development of imperfections due to local differential settlement at the supported base and their effect on the elastic buckling of a thin cylindrical shell under axial compression. M. Barski ${ }^{a}$, J. Kruz elecki ${ }^{\text {b,* }}$ (2005) the authors have presented work on, A thin- walled shell is loaded, by an external pressure and lateral forces causing overall bending moment and the appropriate shearing force. As the equality constraints, the volume of material and the capacity of a shell are considered. D. Redekop* (2005) the author has presented method developed for predicting the buckling properties of an orthotropic shell subjected to a normal pressure. The solution is given within the context of the linearized SandersBudiansky shell buckling theory and applies the differential quadrature method. Numerical results for buckling pressures and mode shapes are given for complete toroidal shells J.C. Virella $^{\mathrm{a}}{ }^{\text {,L.A.Godoy }}{ }^{\mathrm{a}, \mathrm{b}}$, L.E.Suarez ${ }^{\mathrm{a}}$ (2006) the authors have presented investigation of dynamic buckling above ground steel tanks with conical roofs and anchored to the foundation, subjected to horizontal parts of real earthquake records. The study attempts to estimate the critical horizontal peak ground acceleration (Critical PGA), which induces elastic buckling at the top of the cylindrical shell, for the impulsive hydrodynamic response of the tank-liquid system. B.A. Samsam Shariat, M.R. Eslami " (2006) this paper talks about the thermal buckling analysis of rectangular functionally graded plates (FGPs) with geometrical imperfections. The equilibrium, stability, and compatibility equations graded plate are derived using the classical plate theory. Azam Tafreshi * (2006) The author has presented his work on delaminated composite cylindrical shells subject to combined axial compression and pressure are carried out varying the delamination thickness and length, material properties and stacking sequence. Based on the FEA results, the characteristics of the buckling and postbuckling behaviour of delaminated composite cylindrical shells are evaluated. W. Szyc $^{\text {a,* }}$, Z. Laszczyk ${ }^{\text {a }}$, K. Magnucki ${ }^{\text {b }}$ (2006) the authors have presented work on elastic buckling of an open sandwich cylindrical thin-walled panel with three edges simply supported and one edge free under axial compression. On the basis of force and moment equilibrium conditions for the shell element, a set of the fundamental equations are derived. Ömer Civalek (2007) the author has presented his work on the study of numerical solution of three-dimensional analysis of thick rectangular plates. The analysis uses discrete singular convolution (DSC) method to know Free vibration, bending and buckling of rectangular plates. Anton Hübner ${ }^{*}$, Matthias Albiez, Dietmar Kohler, Helmut Saal. (2007) this paper aims 
to mark the discrepancies found in design codes for very long externally pressurized cylindrical shells subjected to uniform external pressure: although the failure is similar to the column buckling subjected to an external compressive load, design codes provide far smaller design values of the buckling load for the cylindrical shell in comparison to the ring. Based on the Euro code 3 (EN 1993-1-6) on shell buckling this study is directed and validated by numerical studies. X. Wang *, K. Dong (2007) this research work comparises of an energy method applied for studying hygrothermal effects on local buckling for different delaminated shapes near the surface of cylindrical laminated shells. The delaminated region is monolayer or multilayer. The effect of non-linear buckling for local delamination of cylindrical laminated shells is obtained by considering transverse displacements of sub-laminate shells. Hsuan-Teh Hu *, Jiing-Sen Yang (2007) this paper talks about the buckling resistance of fiber-reinforced laminated cylindrical panels subjected to uniaxial compressive force. The influences of panel thicknesses, curvatures, aspect ratios, cutouts and end conditions on the optimal fiber orientations and the associated optimal buckling loads of laminated cylindrical panels have been studied. H. Sofiyev ${ }^{\mathrm{a}, *}$, Z. Zerin ${ }^{b}$, A. Korkmaz ${ }^{a}(2008)$ the authors have presented work on the stability of thin three-layered truncated conical shells with functionally graded (FG) layer subjected to nonuniform lateral pressure varying with the longitudinal coordinate. The material properties of the functionally graded layer are assumed to vary continuously through the thickness of the shell. Seong-Hwa Hur, Hee-Jin Son, Jin-Hwe Kweon *, Jin-Ho Choi (2008) the present research work focuses on the postbuckling behavior and failure of composite cylinders subjected to external hydrostatic pressure.The theoretical study consists of finite element method and experiment. A nonlinear finite element program, ACOSwin, is used for postbuckling failure analysis of composite cylinders. E. Magnucka-Blandzi (2008) the author has presented work on axi-symmetrical deflection and buckling of circular porouscellular plate. A critical load and a deflection are determined. The results obtained for porous plates are compared with homogeneous circular plates. T. Hong ${ }^{\text {a }}$, J.G. Teng ${ }^{\text {b,* }}$ (2008) this paper talks about an efficient semi-analytical finite element method for the nonlinear analysis of imperfect shells subject to nonsymmetric loads. Both the applied loads and the initial geometric imperfections may take any form and approximated by Fourier series. P. Malekzadeh ${ }^{\mathrm{a}, \mathrm{b}}$, , A. Ouji ${ }^{\mathrm{c}, \mathrm{d}}$ (2008) the author has presented work on Axisymmetric buckling analysis of laterally restrained thick annular plates using a hybrid numerical method. R. Lo Frano ${ }^{*}$, G. Forasassi (2009) the authors have done investigation on the instabilities of long homogeneous and isotropic thin elastic tubes, with geometric imperfections like eccentricity or ovality, on the buckling behaviour in conditions for which, at present, a complete theoretical analysis was not found in literature. $\mathrm{N}$. Mukaimachia ${ }^{\mathrm{a}, *}$, S. Konosu ${ }^{\mathrm{b}}$ (2009) the authors have presented work on FEAs for large diameter vessels with an external flaw subjected to (1) pure external bending moment, and (2 ) both internal pressure and external bending moment, in order to determine the plastic collapse load by applying the twice-elastic slope (TES) as recommended by the ASME and to determine the buckling load. A.H. Sofiyev* (2010) the author has presented work on buckling analysis of functionally graded material (FGM) circular truncated conical and cylindrical shells subjected to combined axial loads and hydrostatic pressure. Zhi-Min Li ${ }^{a, *}$, Zhong-Qin Lin ${ }^{\mathrm{a}, \mathrm{b}}$ (2010) the authors have presented work on Non-linear buckling and postbuckling of a thick anisotropic laminated cylindrical shell of finite length subjected to lateral pressure, hydrostatic pressure and external fluid pressure. F. Meng, H. Wang, X. Wang *,Z.Li (2010) this research paper aims about the local buckling for the delimitation of an elliptic shape near the surface of piezoelectric laminated shells, where local delaminated sub-shells which are either monolayer and multiplayer, and the geometrical axes of elliptically delaminated sub-shells are not in line with the geometrical main axes of piezoelectric laminated base-shells. M. Shariati , H.R. Allahbakhsh (2010) the authors have presented work on buckling and post-buckling of steel thin-walled semi-spherical shells under different loadings, both experimentally and numerically. Various vertical compression loadings are applied to specimens using methods such as a rigid flat plate and some rigid bars with circular, square and spherical cross sections, a rigid tube, a plate with a hole, and an indented tube. J.H. Wang* , A. Koizumi (2010) the authors have presented work on the bucking of cylindrical shells with longitudinal joint with experimental and numerical analysis. It was stated that the buckling behavior of cylindrical shells with longitudinal joints under lateral external pressure is not only related to its dimension, but also longitudinal joint and an imperfection. Tohid Ghanbari Ghazijahani a, Hossein Showkati ${ }^{b, *}{ }^{*}$ 2011) the authors have studied buckling behavior of conical shell reducers under uniform peripheral pressure and evaluated by experimentation. Along with this FEA simulations as well as theoretical predictions were taken into account to compare buckling load and modes of deformation. S.K. Panda ${ }^{a}$, B.N. Singh ${ }^{\text {b** }}$ (2011) the authors have studied nonlinear free vibration behavior of single/doubly curved shell panel is addressed within the post-buckled state. Thermal post-buckling of shell panel is accounted for a uniform temperature. A mathematical model is developed 1 by introducing the geometric nonlinearity based on higher order shear deformation theory. Izzet U. Cagdas ${ }^{\mathrm{a},{ }^{*}, 1}$, Sarp Adali ${ }^{\mathrm{b}}$ (2011) the authors have studied Buckling phenomenon of cross-ply cylinders under hydrostatic pressure with a semianalytical finite element analysis based on a first order shear deformable shell theory. After solving numerous problems the numerical results are compared with the analytical results available in the literature. F. Albermani , H. Khalilpasha, H. Karampour (2011) the authors have studied buckle propagation in deep sub-sea pipelines. Experimental results are presented using ring squash tests and hyperbaric chamber tests, and are compared with a modified analytical solution and with numerical results using finite element analysis. The 
experimental investigation was conducted using commercial aluminum pipes Preliminary analysis of these pipelines shows that a substantial increase in buckling capacity.

\section{CONCLUSIONS}

Since buckling can be simply defined as the instability of any structure. The present paper summarizes study of buckling phenomenon in structures like thin -thick shell and plates by authors from different background. All the authors have presented research work in terms of mathematical study supported by Finite Element method as well as in some cases conducting experimental test to compare the results. The study shows different types of buckling such as plastic, dynamic, buckling of cylindrical shells with axial load, and external pressure there causes \& effects on the structural members. Some of the authors have presented new set of design rules for critical cases of buckling such as spherical shell etc.

\section{REFERENCES}

[1] W. Guggenberger, R Grenier, J. M. Rotter, The behavior of locally-supported cylindrical shells: unstiffened shells, Journal of Constructional Steel Research, 56 (2), 2000, 175-197.

[2] Rodney Pinna, Beverley F. Ronalds, Hydrostatic buckling of shells with various boundary conditions, Journal of Constructional Steel Research, 56(1), 2000, $1-16$.

[3] J.G. Teng, F. Chan, Elastic buckling strength of Tsection transition ring beams in steel silos and tanks, Journal of Constructional Steel Research, 56(1), 2000, 69-99.

[4] S. Kyriakides, T.A. Netto, on the dynamics of propagating buckles in pipelines, International Journal of Solids and Structures 37(46-47), 2000, 6843-6867.

[5] G. Michel , A. Limam, J.F. Jullien, Buckling of cylindrical shells under static and dynamic shear loading, Engineering Structures, 22(5), 2000, 535-543.

[6] G. Michel , A. Combescure ,J.F. Jullien, Finite Element simulation of dynamic buckling of cylinders subjected to periodic shear, Thin-Walled Structures ,36 (2), 2000, 111-135.

[7] Hui-Shen Shen, Post buckling of shear deformable cross-ply laminated cylindrical shells under combined external pressure and axial compression, International Journal of Mechanical Sciences, 43(11), 2001, 24932523.

[8] Mark W. Hilburger, Vicki O. Britt, Michael P. Nemeth, Buckling behavior of compression-loaded quasi-isotropic curved panels with a circular cut out, International Journal of Solids and Structures, 38 (9), 2001, 1495-1522.

[9] I.P. Pasqualino' S.F. Estefen, A non-linear analysis of the buckle propagation problem in deepwater pipelines, International Journal of Solids and Structures, 38(4647), 2000, 8481-8502.
[10] Carl T.F. Ross, Andrew P.F. Little, The buckling of a corrugated carbon fibre cylinder under external hydrostatic pressure, Ocean Engineering, 28(10), 2001, 1247-1264.

[11] Jianghong Xue, Michelle S. Hoo Fatt, Buckle propagation in pipelines with non-uniform thickness, Ocean Engineering, 28 (10), 2001, 1383-1382.

[12] Gyeong-Hoi Koo , Bong Yoo, Jong Bum Kim, Buckling limit evaluation for reactor vessel of KALIMER liquid metal under lateral seismic loads, International Journal of Pressure Vessel \& Piping , 8 ( 5), 2001, 321-330.

[13] X. H. Shi , Y. G. Gao, Generalization of response number for dynamic plastic response of shells subjected to impulsive loading, International Journal of Pressure Vessel \& Piping, 78 (6), 2001, 453-460.

[14] Michelle S. Hoo Fatt, Jianghong Xue, Propagating buckles in corroded pipelines, Marine Structures, 14 ( 6), 2001, 571-592.

[15] X. Wang, G. Lu, D.G. Xiao, Non-linear thermal buckling for local delamination near the surface of laminated cylindrical shell, International Journal of Mechanical Sciences, 44(5),2002. 947-965.

[16] Walter Wunderlich , Ursula Albertin, Buckling behaviour of imperfect spherical shells, International Journal of Non-Linear Mechanics, 37(4-5), 2002, 589604.

[17] Mark W. Hilburger, James H. Starnes Jr., Effects of imperfections on the buckling response of compression-loaded composite shells, International Journal of Non-Linear Mechanics, 37 (4-5),2002, 623643.

[18] Seung-Eock Kim, Chang-Sung Kim, Buckling strength of the cylindrical shell and tank subjected to axially compressive loads, Thin-Walled Structures ,40 (4), 2002, 329-353.

[19] J. Błachut, Buckling of externally pressurised barrelled shells: a comparison of experiment and theory, International Journal of Pressure Vessels and Piping, 79 (7), 2002, 507-517.

[20] C.A. Schenk, G.I. Schuëller, Buckling analysis of cylindrical shells with random geometric imperfections, International Journal of Non-Linear Mechanics 38(7), 2003, 1119-1132.

[21] C.T.F. Ross , Bak Hock Huat, Tay Boon Chei , Chai Min Chong , M.D.A. Mackney, The buckling of GRP hemi-ellipsoidal dome shells under external hydrostatic pressure, Ocean Engineering, 30 (5), 2003, 691-705.

[22] Cho-Chung Liang, Hung-Wen Chen, Optimum design of fiber-reinforced composite cylindrical skirts for solid rocket cases subjected to buckling and overstressing constraints, Composites: Part B, 34(3) 2003, 273-284.

[23] M. Özakca, N. Taysi, F. Kolcu, Buckling analysis and shape optimization of elastic variable thickness circular and annular plates-I. Finite element formulation, Engineering Structures, 25 (2), 2003, 181-192. 
[24] P.K. Das, A. Thavalingam, Y. Bai, Buckling and ultimate strength criteria of stiffened shells under combined loading for reliability analysis, Thin-Walled Structures, 41(1), 2003, 69-88.

[25] Azam Tafreshi , Tobias Oswald, Global buckling behaviour and local damage propagation in composite plates with embedded delaminations, International Journal of Pressure Vessels and Piping, 80(1),2003, 920.

[26] G.H. Nie , Analysis of non-linear behaviour of imperfect shallow spherical shells on pasternak foundation by the asymptotic iteration method, International Journal of Pressure Vessels and Piping, 43(2),2003, 229-235.

[27] L. Grünitz, The effect of welding on the buckling behaviour of a spherical cap, International Journal of Pressure Vessels and Piping, 43(4),2003, 237-241.

[28] N. Ganesan , V. Pradeep, Buckling and vibration of circular cylindrical shells containing hot liquid, Journal of Sound and Vibration, 287(4-5), 2005, 845-863.

[29] Z.G. Wei, J.L. Yu, R.C. Batra, Dynamic buckling of thin cylindrical shells under axial impact, International Journal of Impact Engineering, 32(1-4), 2005, 575-592.

[30] B. Skalleruda, K. Holthe , B. Haugen, Thin shell and surface crack finite elements for simulation of combined failure modes, Computer Methods in Applied Mechanics and Engineering, 194(21-14), 2005, 2619-2640.

[31] Roberto Brighenti, Numerical buckling analysis of compressed or tensioned cracked thin plates, Engineering Structures, 27(2)2005, 265-276.

[32] B.P. Patel, K.K. Shukla , Y. Nath, Thermal postbuckling analysis of laminated cross-ply truncated circular conical shells, Composite Structures, 71(1),2005, 101-114.

[33] Henrique Santo, Cristóvão M. Mota Soares, Carlos A. Mota Soares , J.N. Reddy, A semi-analytical finite element model for the analysis of laminated 3D axisymmetric shells: Bending, free vibration and buckling, Composite Structures, 71(3-4),2005, 273281.

[34] J. Mark F.G. Holst", J. Michael Rotter, Axially compressed cylindrical shells with local settlement, Thin-Walled Structures, 43(5), 2005, 811-825.

[35] M. Barski, J. Krużelecki , Optimal design of shells against buckling under overall bending and external pressure, Thin-Walled Structures, 43(11), 2005, 1677 1698.

[36] D. Redekop, Buckling analysis of an orthotropic thin shell of revolution using differential quadrature, International Journal of Pressure Vessels and Piping, 82(8),2005, 618-624..

[37] J.C. Virella ,L.A.Godoy , L.E.Suarez, Dynamic buckling of anchored steel tanks subjected to horizontal earthquake excitation, Journal of Constructional Steel Research, 62(6),2006,521-531.
[38] B.A. Samsam Shariat, M.R. Eslami, Thermal buckling of imperfect functionally graded plates, International Journal of Solids and Structures, 43 (14-15),2006, 4082-4096

[39] Azam Tafreshi, Delamination buckling and postbuckling in composite cylindrical shells under combined axial compression and external pressure, Composite Structures, 72 (4), 2006, 401-418.

[40] W. Szyc , Z. Laszczyk , K. Magnucki , Elastic buckling of an axially compressed sandwich cylindrical panel with three edges simply supported and one edge free, Thin-Walled Structures, 44( 8), 2006 910-918.

[41] Ömer Civalek, Free vibration and buckling analyses of composite plates with straight-sided quadrilateral domain based on DSC approach, Finite Elements in Analysis and Design, 43, 2007, 1013-1022

[42] Anton Hübner, Matthias Albiez, Dietmar Kohler, Helmut Saal, Buckling of long steel cylindrical shells subjected to external pressure, Thin-Walled Structures, 45( 1), 2007, 1-7.

[43] X. Wang, K. Dong, Local buckling for triangular and lemniscate delaminations near the surface of laminated cylindrical shells under hygrothermal effects, Composite Structures, 79, 2007, 67-75.

[44] Hsuan-Teh Hu, Jiing-Sen Yang, Buckling optimization of laminated cylindrical panels subjected to axial compressive load, Composite Structures, 81( 3), 2007, 374-385.

[45] H. Sofiyev , Z. Zerin, A. Korkmaz, The stability of a thin three-layered composite truncated conical shell containing an FGM layer subjected to non-uniform lateral pressure, Composite Structures, 85,2008, 105115.

[46] Seong-Hwa Hur, Hee-Jin Son, Jin-Hwe Kweon, JinHo Choi, Postbuckling of composite cylinders under external hydrostatic pressure, Composite Structures, 86,(1-3), 2008, 114-124.

[47] E. Magnucka-Blandzi, Axi-symmetrical deflection and buckling of circular porous-cellular plate, Thin-Walled Structures, 46(3), 2008, 333-337.

[48] T. Hong , J.G. Teng, Imperfection sensitivity and postbuckling analysis of elastic shells of Revolution, Thin-Walled Structures,46(12), 2008, 1338-1350.

[49] P. Malekzadeh , A. Ouji, Axisymmetric buckling analysis of laterally restrained thick annular plates using a hybrid numerical method, International Journal of Pressure Vessels and Piping, 85(11), 2008,789-797.

[50] R. Lo Frano , G. Forasassi, Experimental evidence of imperfection influence on the buckling of thin cylindrical shell under uniform external pressure, Nuclear Engineering and Design, 239 ,2009, 193-200.

[51] N. Mukaimachia, S. Konosu, Buckling assessment procedure for large diameter vessel with local thin area subjected to combined pressure and external moment, Nuclear Engineering and Design, 239(2), 2009, 221230 . 
[52] A.H. Sofiyev, Buckling analysis of FGM circular shells under combined loads and resting on the Pasternak type elastic foundation, Mechanics Research Communications, 37, 2010, 539-574.

[53] Zhi-Min Li , Zhong-Qin Lin, Non-linear buckling and postbuckling of shear deformable anisotropic laminated cylindrical shell subjected to varying external pressure loads, Composite Structures, 92( 2),2010, 553-567.

[54] F. Meng, H. Wang, X. Wang, Z. Li, Elliptically delaminated buckling near the surface of piezoelectric laminated shells under electric and thermal loads, Composite Structures, 92(3), 2010, 684-690.

[55] M. Shariati , H.R. Allahbakhsh, Numerical and experimental investigations on the buckling of steel semi-spherical shells under various loadings, ThinWalled Structures, 48(8), 2010, 620-628.

[56] J.H. Wang, A. Koizumi, Buckling of cylindrical shells with longitudinal joints under external pressure, ThinWalled Structures, 48(12), 2010, 897-904.

[57] Tohid Ghanbari Ghazijahani, Hossein Showkati, Experiments on conical shell reducers under uniform external pressure, Journal of Constructional Steel Research, 67,(10), 2011,1506-1515.

[58] S.K. Panda , B.N. Singh, Large amplitude free vibration analysis of thermally post-buckled composite doubly curved panel using nonlinear FEM, Finite Elements in Analysis and Design, 47(4), 2011, 378386.

[59] Izzet U. Cagdas, Sarp Adali, Buckling of cross-ply cylinders under hydrostatic pressure considering pressure stiffness, Ocean engineering, 38(4), 2011, 559-569.

[60] F. Alberani, H. Khalilpasa, H. Karampor, Propagation buckling in deep sub-sea pipelines, Engineering Structures, 33(9), 2011, 2547-2553.

\section{BIOGRAPHIES}

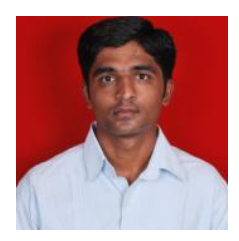

Amit M. Patil is currently working as Asst. Professor in Department of Mechanical Engineering, at Pad. DR D Y Patil Institute Engineering \& Technology, Pimpri, Pune. $\mathrm{He}$ has completed M.E (Design Engineering).

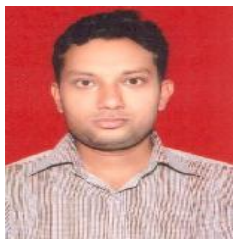

Amol M. Kolhe is currently working as Asst. Professor in Department of Mechanical Engineering, at Pad. DR D Y Patil Institute Engineering \& Technology, Pimpri, Pune. He has completed M.E (CAD/CAM)

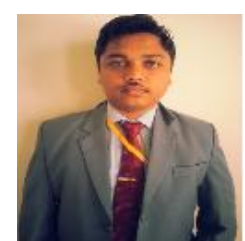

Abdul Sayeed AW Shaikh is currently working as Asst. Professor in Department of Mechanical Engineering, at P.R. Pote (Patil) College of Engineering \&
Management; Amravati. He has completed M.E (Design Engineering). 